\title{
Dynamic Simulation Analysis of Track Tension and the Influencing Factors of Deep-Sea Tracked Mining Vehicle
}

\author{
Fan Beibei $(i)$ and Liao Naixing \\ School of Mechatronic Engineering and Automation, Shanghai University, Shanghai, China \\ Correspondence should be addressed to Fan Beibei; fanbeibei@shu.edu.cn
}

Received 12 March 2021; Accepted 7 October 2021; Published 5 January 2022

Academic Editor: M.I. Herreros

Copyright (c) 2022 Fan Beibei and Liao Naixing. This is an open access article distributed under the Creative Commons Attribution License, which permits unrestricted use, distribution, and reproduction in any medium, provided the original work is properly cited.

\begin{abstract}
The deep-sea mining miner requires good passability to operate in complex and changeable terrain environment of the seabed. Among them, the track tension is an important factor to ensure the normal running of the vehicle. Aiming at the complex track tension problem on track link, the forces on each component of the tracked system were analyzed, and the theoretical formulas of track tension were established. The theoretical estimation and dynamic simulation of track tension in uniform speed were carried out by using the multibody dynamics model of the tracked vehicle, and the rationality of the theoretical estimation formula was verified. The influencing factors of track tension also were analyzed, and the significance of each factor on track was discussed by dynamic simulation. The results provided a theoretical basis for design of tracked vehicles.
\end{abstract}

\section{Introduction}

The ocean is a huge resource gathering place. It not only contains a lot of biological resources and energy, but also contains rich mineral resources. Mineral resources are the material basis for human survival, and the exploitation of deepsea mineral resources is of great significance to social and economic development and national resource security. At present, China has gradually shifted from ocean resources investigation to the development stage of exploration and mining equipment. The working environment of the deep-sea mining vehicle is very harsh and complicated. During the mining process, the vehicle mainly uses the sediments at the deep-sea surface layer $15-20 \mathrm{~cm}$ as the main bearing layer and traction layer. Due to the advantages of low ground pressure, high adhesion, good stability, and strong protection performance, the tracked vehicle has high off-road maneuverability and passability. In other words, the track structure ensures that the vehicle can pass through the rugged terrain smoothly at high speed. Therefore, in the research of deep-sea mining vehicles, the track type travel mechanism is widely adopted.

As one of the important components of track type running mechanism, the function of the track is to ensure the passability of the vehicle during driving and reduce the driving resistance. It supports the road wheels and provides a continuous rolling track. By interacting with the ground, the track transfers the traction, adhesion, and braking force of the ground to the vehicle body, so that the vehicle can move normally. The track tension has a great influence on the performance of track driving system. If the tension force is too large, the track stiffness is too large to play a buffer role, which will increase the friction between the track and chassis components, causing serious energy consumption and the risk of belt breakage; if the tension force is too small, the track will be loose, leading to taking off the belt and rake teeth, resulting in track failure and vehicle paralysis.

Studying the distribution of the tension on the track link can not only provide a theoretical basis for the research of the track tension, but also provide a reference for the design and development of tracked vehicles. However, the track tension changes with the driving conditions, and there are many influencing factors, which makes the theoretical modelling and analysis difficult. In order to make the track travel mechanism adapt to the environment better and improve its stability and efficiency in the operation process, it is necessary to study the change of the tension force when 
it works in typical environment. Therefore, the calculation and optimization of the tension force become the focus of the research.

\section{Related Work}

In Ma and Perkins [1], a mathematical model is proposed for dynamic simulation of tracked vehicle based on track-wheelterrain interaction. One of the main features of this model is that it adopts a uniform approach to deal with the contact between the track and the road wheels and the track and the terrain, which significantly simplifies the problem formulation and reduces difficulties in computing points of track wheel and track-terrain separation. In Matej [2], a genetic algorithm is implemented by using Java language to find the optimal parameters of the tensioning system and verify the results via multibody dynamics simulation using the MSC.ADAMS/View system. The auxiliary track tensioning system is used to reduce the variance of track tension, which means that the value of the track tensioning force is closer to its desired, predefined, and constant value during the whole simulation. Huh et al. [3-5] design an indirect track tension monitoring system. The estimated track tension results demonstrate good agreement with the true values generated not only from the multibody dynamics tool but also with an experimental set-up. The estimation performance demonstrates the feasibility of online and real-time track tension monitoring based on the remotely measurable signals such as tensioner position and pressure, sprocket angular velocity, vehicle velocity, and acceleration. In Chalupa et al. [6], a method is introduced to establish the kinematic mechanism model of tracked vehicle in simulation system, which consists of two parts: geometrical part and contact computational part. The purpose of the simulation is to analyze the influence of changes in track constructive parameters on track vehicle course stability. Their work quantified the influence of changes of track preloaded values on demanded torque changes of driving sprocket. In Mżyk [7], the active track tensioning system is designed and the effect of different idler displacements on the chassis vibration is simulated.

In Huang et al. [8,9], the distribution of track tension on the track link is studied, and the theoretical estimation model of track tension was built depending on the free body diagram of the idler, upper track, sprocket, and road wheels. And the relation of track tension and outer loads was also analyzed. Wang et al. [10] proposed a constant hydraulic driving force control method for track vehicles in the driving process, which can reduce the dynamic track tension and keep it as stable as possible without increasing the pretension. Different from conventional tensioner, the force is adjusted in real time by a hybrid controller. In addition, the control system makes track tension and perimeter stably kept in a smaller range, which reduces the deformation of track rubber bushing. And it is also beneficial to improve the service life of tracks and decreases the risk of peel-off and breakage of tracks. Wang et al. [11] proposed a multidrive track link structure, established a mathematical model of the track system, and studied the distribution of track tension. The combined simulation results of RecurDyn and Simulink showed that the structure has more uniform tension distribution and then traditional structures. Particularly, under the high-speed condition, the maximum tension can be reduced by $28 \mathrm{kN}-36 \mathrm{kN}$ and the transmission efficiency can be improved by $10 \%-16 \%$. In Pan et al. [12], a mathematical model for components is established by analyzing the forces acting on components of the track system according to the structure of track system in tracked vehicle. And the formulas were verified by comparing with the simulation results with RecurDyn dynamic model.

Regardless of whether foreign or domestic research on the tension force of the tracked vehicle, the road surface of the vehicle is mostly solid road, ignoring the impact of the soft ground road on the force of the track. Based on the above research, this paper analyzes the soil properties of the deep-sea sediments and takes the vehicle sinking phenomenon and the interaction between the vehicle and the ground during the driving process into account, the theoretical model of track tension is established, and the results are compared with the dynamic simulation results.

\section{Estimation of the Track Tension}

3.1. Analysis of Track-Terrain Interaction on Soft Soil. Due to the complex physical and mechanical properties of soft soil, the performance of the vehicle is greatly disturbed during the driving process, which causes the vehicle to sink and increase the driving resistance. Under the action of tracked vehicle, the soil compaction is usually accompanied with lateral movement and displacement, so the affected area under the interaction between the track and the soil is 3D. Based on the analysis and summary of previous scholars' research, McKyes and Ali [13] proposed a wedge-shaped section model based on three-dimensional space to analyze the shear characteristics of baffles on soil.

The mechanical analysis of the baffle-terrain interaction is shown in Figure 1, including the width of the blade $w$, the operating depth $d$, the density of soil $\gamma$, the soil-metal friction angle on the blade surface $\delta$, the internal friction angle $\psi$, the soil cohesion $c$, the surface forces $p, p_{1}, p_{2}$, the rake angle of the blade from the horizontal $\alpha$, and failure angle $\beta$. Based on the above mechanical analysis, McKyes used the following equation to predict the shear resistance between baffle and soil:

$$
p=\left(\gamma d^{2} N_{\gamma}+c d N_{c}+q d N_{q}\right) w
$$

where $q$ is the surface surcharge pressure and $\beta$ is chosen for the minimum $N_{\gamma}$ in the same equation by trial and error.

The three-dimensional model is applied to the study of track-terrain interaction, and the parameters are transformed. According to the structure of the track segment, the grouser is usually perpendicular to the caterpillar; that is, the rake angle of the blade from the horizontal $\alpha=90^{\circ}$, the height of the grouser $h=d$, and the width of the segment $B=w[14]$. The schematic diagram of force analysis of the baffle and parameters is shown in Figure 2, including adhesion between the top of the grouser and soil $F_{1}$, adhesion between the bottom of track segment and soil, and pressure on side $\mathrm{BD}$ surface $F_{34}=p$. 


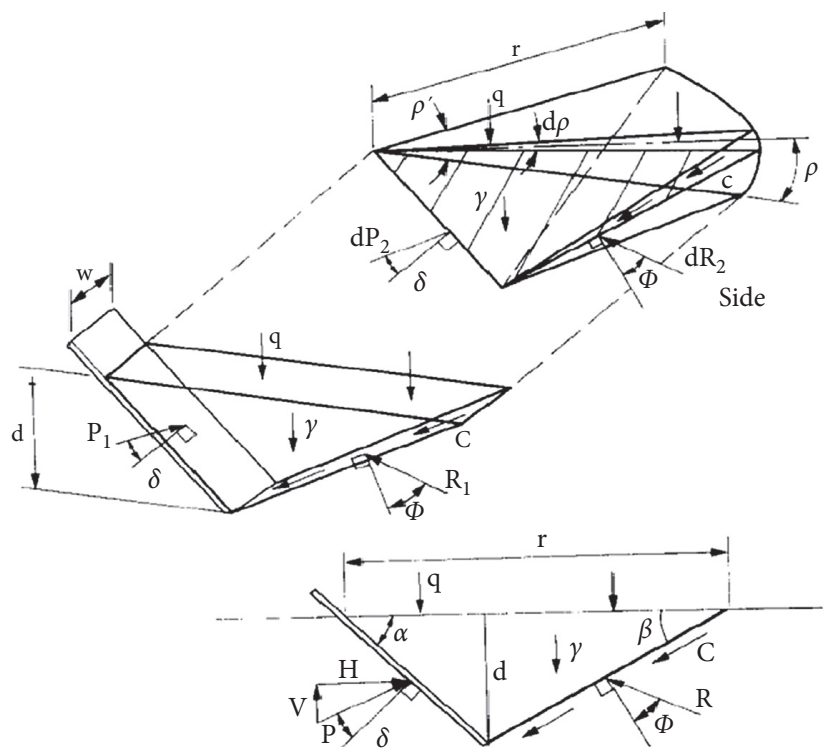

FIgURE 1: Mechanical analysis of the baffle-terrain interaction.

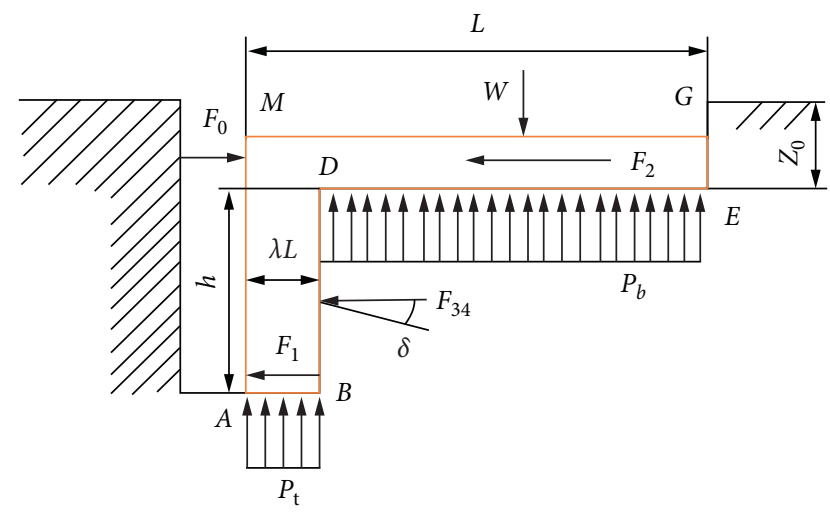

Figure 2: Schematic diagram of force analysis of the baffle and parameters.

Although $p_{t}$ and $p_{b}$ are the compressive stress of the track to the terrain, the compression of the grouser and the track segment to the terrain is different, so the distribution cannot be carried out according to the uniform load, and the pressure-sinkage expression should be used for calculation:

$$
\begin{aligned}
& p_{t}=\left(\frac{k_{c}}{B+k_{\psi}}\right)\left(h+z_{0}\right)^{n}, \\
& p_{b}=\left(\frac{k_{c}}{B+k_{\psi}}\right) z_{0}^{n},
\end{aligned}
$$

where $k_{c}$ is deformation coefficient of soil cohesion, $k_{\psi}$ is coefficient of soil friction deformation, $n$ is soil deformation coefficient, and $z_{0}$ is soil settlement.

By analyzing the crawler shoe and the soil under shear separately, it can be concluded that

$$
F_{s}=F_{1}+F_{2}+F_{34}
$$

According to Coulomb's theory,

$$
\begin{aligned}
& F_{1}=\lambda \operatorname{LB}\left(c_{a}+p_{t} \tan \delta\right)\left(1-e^{-i / k}\right), \\
& F_{2}=(1-\lambda) \operatorname{LB}\left(c_{a}+p_{b} \tan \delta\right)\left(1-e^{-i / k}\right),
\end{aligned}
$$

where $c_{a}$ is soil cohesion, $i$ is slippage rate, $k$ is soil deformation coefficient, $k=k_{c} / B+k_{\psi}$, and $\lambda$ is the ratio of the thickness of the grouser to the pitch of the track segment.

When the slippage rate $i$ is unknown, the shear resistance can also be predicted by observing the soil failure. Therefore, the shear resistance can be obtained by combining equations (1) to (6):

$$
F_{s}=B\left\{c_{a} L+L k\left[\lambda\left(h+z_{0}\right)^{n}+(1-\lambda) z_{0}^{n}\right] \tan \delta+\left(\gamma h^{2} N_{\gamma}+c h N_{c}+q h N_{q}\right)\right\}
$$

3.2. Theoretical Models for the Track Tension. The track subsystem of tracked vehicle, which is shown in Figure 3, includes sprockets, support rollers, idlers, road wheels, and track shoes. In the analysis and calculation of track tension, the track subsystem is divided into two parts: road wheels and idler. The inertia force and moment of each wheel and the gravity of track shoes are ignored because the magnitude of them is much less than the track tension. $F_{D 1}$ and $F_{D 2}$ 


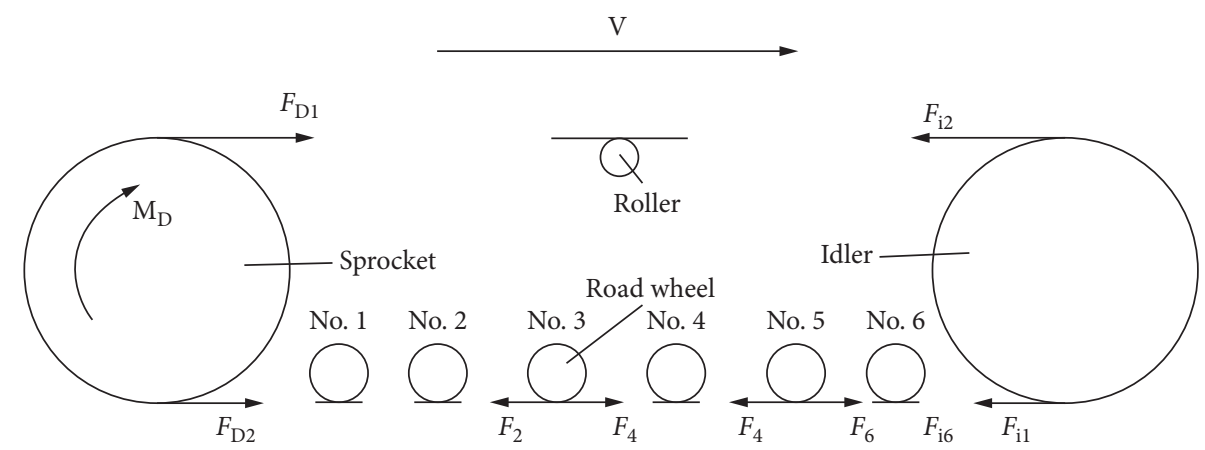

FIgURE 3: Track tension variation along the track path.

describe track tension around the sprocket and $M_{D}$ represents torque of the sprocket. This leads to equations written as

$$
F_{D 2}=F_{D 1}+\frac{M_{D}}{r_{D}} .
$$

When the gravity and vibration of the track shoes between the sprocket and the idler and the influence of the support roller were ignored, it is considered that $F_{D 1}$ and $F_{i 2}$ are approximately equal, $F_{i 1}$ and $F_{i 6}$ are approximately equal, $F_{i 1}$ and $F_{i 2}$ represent track tension around the idler, and $F_{i 6}$ is track tension of track segments under No. 6 road wheel; the expression can be given as follows:

$$
\begin{aligned}
& F_{D 1} \approx F_{i 2}, \\
& F_{i 1} \approx F_{i 6} .
\end{aligned}
$$

3.2.1. Track Tension Estimation around the Idler. The idler is installed on the track tension mechanism, which is used to support and change the movement direction of the upper track and adjust the track tension by moving the idler to tighten or loosen the track. Take the idler as free body; get the geometry structure and force situation of the idler as shown in Figure 4 . The equations of motion for the idler can be written as follows:

$$
\begin{aligned}
& m \ddot{x}=F_{t}+F_{\mathrm{ce}}+F_{s}+F_{f i}-F_{i 1}-F_{i 2}, \\
& m \ddot{y}=F_{\mathrm{yi}}+G_{i}-N_{i}, \\
& I_{i} \dot{\omega}_{i}=\left(F_{i 2}+F_{s}+F_{f i}-F_{i 1}\right) r_{i}, \\
& F_{\mathrm{ce}}=2 \rho\left(\omega_{i} r_{i}\right)^{2},
\end{aligned}
$$

where $F_{t}$ is a pretension, $G_{i}$ is the gravity of the idler, $F_{s}$ is the force of soft soil to the track segments, $F_{f i}$ represents friction between idler and track, $F_{f i}=u N_{i}, F_{c e}$ is centrifugal force of a track segment wrapping around the idler, $\omega_{i}$ is the rotation velocity of the idler, $m$ is the mass of the idler, $I_{i}$ is the mass

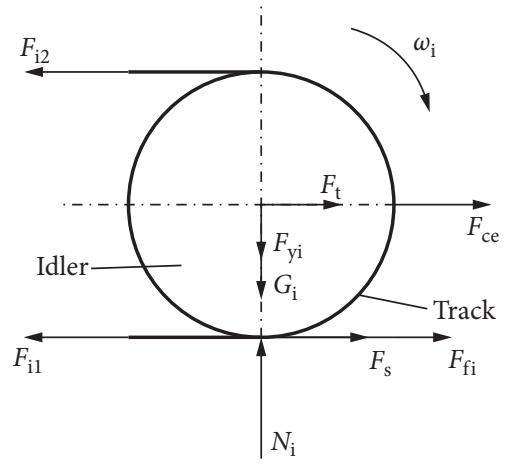

Figure 4: Free body diagram of the idler.

moment of inertia of the idler, and $\rho$ is unit mass of track segment.

By combining (10) to (14), the track tensions $F_{i 1}$ and $F_{i 2}$ are written as

$$
\begin{aligned}
& F_{i 2}=\frac{F_{t}+F_{\mathrm{ce}}-m \ddot{x}+I_{i} \dot{\omega}_{i} / r_{i}}{2}, \\
& F_{i 1}=F_{i 2}+F_{s}+F_{f i}-I_{i} \dot{\omega}_{i} / r_{i} .
\end{aligned}
$$

3.2.2. Track Tension Estimation around the Road Wheel. During vehicle movement, the road wheels and the track shoes are regarded as a whole. There are six road wheels on each side. Only one of them is free body to be analyzed because the center lines of the six road wheels are parallel to the ground.

Figure 5 represents the free body diagram of the road wheel where $F_{j-1}$ and $F_{j+1}$ are the track tensions around the road wheel and $F_{R x}$ and $F_{R y}$ are longitudinal and lateral supporting of the road wheels. $G_{j}$ is the gravity of the road wheel, $N_{R j}$ is the normal contact force between the road wheel and track segments, $F_{f j}$ represents friction between the road wheel and track, $F_{f j}=u N_{R j}$, and $\omega_{R j}$ is the rotation velocity of the road wheels. $m_{j}$ is the mass of the road wheel; $I_{j}$ is the mass moment of inertia of the road wheels. The equations of motion for the road wheel can be written as follows: 


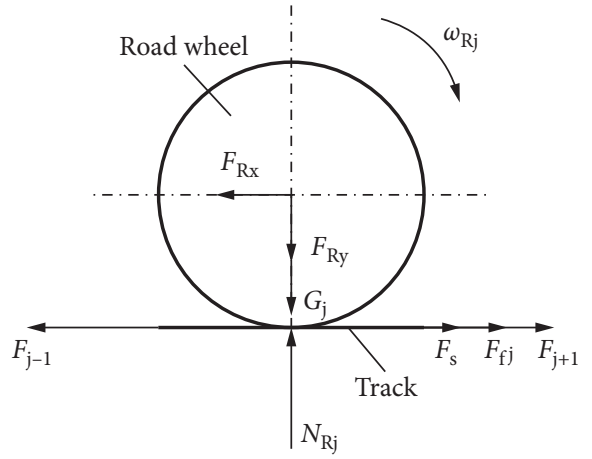

Figure 5: Free body diagram of the road wheel.

$$
\begin{aligned}
m_{j} \ddot{y}_{j} & =F_{R y}+G_{j}-N_{R j}, \\
I_{j} \dot{\omega}_{j} & =\left(F_{j-1}-F_{j+1}-F_{f j}-F_{s}\right) r_{j} .
\end{aligned}
$$

By combining (8), (9), (15), and (16), the track tensions $F_{D 1}$ and $F_{D 2}$ can be calculated from the following equations:

$$
\begin{gathered}
F_{i 2}=\frac{F_{t}+F_{\mathrm{ce}}-m \ddot{x}+I_{i} \dot{\omega}_{i} / r_{i}}{2}, \\
F_{D 2}=F_{i 2}=\frac{F_{t}+F_{\mathrm{ce}}-m \ddot{x}+I_{i} \dot{\omega}_{i} / r_{i}}{2}+\frac{M_{D}}{r_{D}} .
\end{gathered}
$$

By combining (10) and (15) to (18), the track tension around No. 5 is written as

$$
\begin{aligned}
& F_{4}=F_{i 1}+2\left[u\left(F_{R y}+G_{5}-m_{5} \ddot{y}_{5}\right)+\frac{I_{5} \dot{\omega}_{5}}{r_{5}}+F_{s}\right], \\
& F_{6}=F_{i 1}+u\left(F_{R y}+G_{5}-m_{5} \ddot{y}_{5}\right)+\frac{I_{5} \dot{\omega}_{5}}{r_{5}}+F_{s} .
\end{aligned}
$$

\section{Simulation Results}

The computational simulating system RecurDyn is used for the computational modelling and simulating. This system can be used for the analysis and dynamic characteristics of the modelling mechanic system and its animation. The dynamic model is established by RecurDyn, the rotation velocity, angular acceleration, acceleration, and track tension that can be obtained from simulation results; by substituting those variables into (19) and (21), the accuracy of the mathematical model is verified by comparison with simulation results in RecurDyn.

4.1. Road Parameters Setting. In the dynamic simulation of the established tracked vehicle model, under the premise of the same level road conditions, different simulation results will be obtained when the vehicle runs on the solid road and the clayey road. Therefore, it is necessary to establish the corresponding road documents and set the pavement soil parameters. Deep-sea mud has the characteristics of highwater content, small internal friction angle, high liquid limit, high plasticity, large void ratio, low strength and low gravity,
TABLE 1: The parameters of the surface soil of deep-sea bed.

\begin{tabular}{lcc}
\hline Parameters & Variable & Value \\
\hline Soil cohesion modulus & $k_{c}$ & 21.067 \\
Soil friction deformation modulus & $k_{\psi}$ & 0.066 \\
Soil deformation index & $n$ & 0.463 \\
Cohesive force & $c$ & $12.6 \mathrm{KPa}$ \\
Soil internal friction & $\psi$ & $3.1^{\circ}$ \\
Shearing deformation modulus & $k$ & 55 \\
\hline
\end{tabular}

etc.; according to the formation characteristics, sedimentary characteristics, and composition types of deep-sea surface sediments, deep-sea mud belongs to the category of clayey soil [15-17]. The settings of soil parameters are shown in Table 1.

4.2. Comparisons of Track Tension around the Sprocket $\left(F_{D 1}\right)$. The track tension is simulated and analyzed under the condition of uniform speed. Assuming that the pretension of the track is $47600 \mathrm{~N}$, the angular velocity of the sprocket is $2 \pi \mathrm{rad} / \mathrm{s}$, and the road surface of the vehicle is the clayey road; the change curve of the tension around sprocket is shown in Figure 6 . The average value of the tension force $\left(F_{D 1}\right)$ calculated by the formula derived in this paper is $23802.36 \mathrm{~N}$, and the average value of simulation is 24348.88 $N$. It can be seen from Figure 6 that the change rules of the two curves are consistent, meaning that the accuracy of the theoretical formula is good.

The structure of the track segments, the engagement between the track and the sprocket, and the dynamic load caused by the moving process of the tracked vehicle are taken into account during dynamic simulation of tracked vehicle under constant speed, leading to the change of track tension that is a random process. The above factors are ignored when deducing the theoretical estimation formula of track tension, while the dynamics simulation of tracked vehicle using RecurDyn takes these factors into account. Therefore, the simulation results fluctuate more than the theoretical estimation results, but the overall change rules of the two are consistent, and the error is also within the range.

4.3. Comparisons of Track Tension around No. 5 Road Wheel $\left(F_{4}\right)$. The dynamic track tension around NO. 5 is presented in Figure 7 . The average value of the tension force $\left(F_{4}\right)$ calculated by the formula derived in this paper is 24559.86 $\mathrm{N}$; the average value of simulation is $24298.76 \mathrm{~N}$; according to the [8], $F_{4}$ can be calculated as $23359.87 \mathrm{~N}$. The results obtained from (14) have a higher fit with the simulation results. It also can be observed from Figure 7 that the curve variation rule of (21) is more in line with the simulated curve.

Under the action of the crawler of the tracked vehicle, the soil will be compacted and the interaction between the soil and the track segments occurs. The angle of internal friction of soil will hinder the moving of tracked vehicle. In [8], the resistance of soft soil to the vehicle was ignored when deriving the theoretical formula of track tension of each part. In this paper, the factor is taken into account on the basis of 


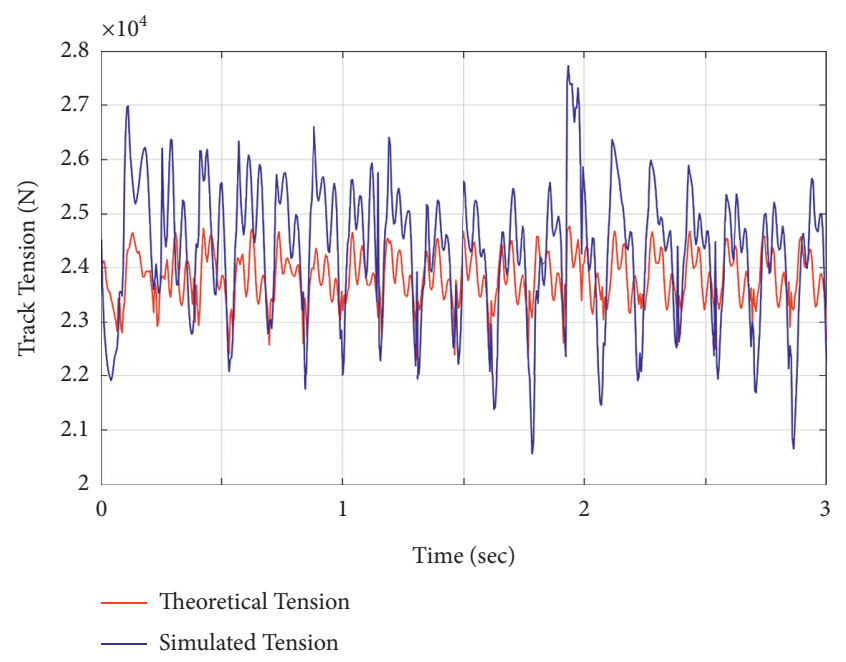

FIgURE 6: Track tension $\left(F_{D 1}\right)$ estimation during slow speed.

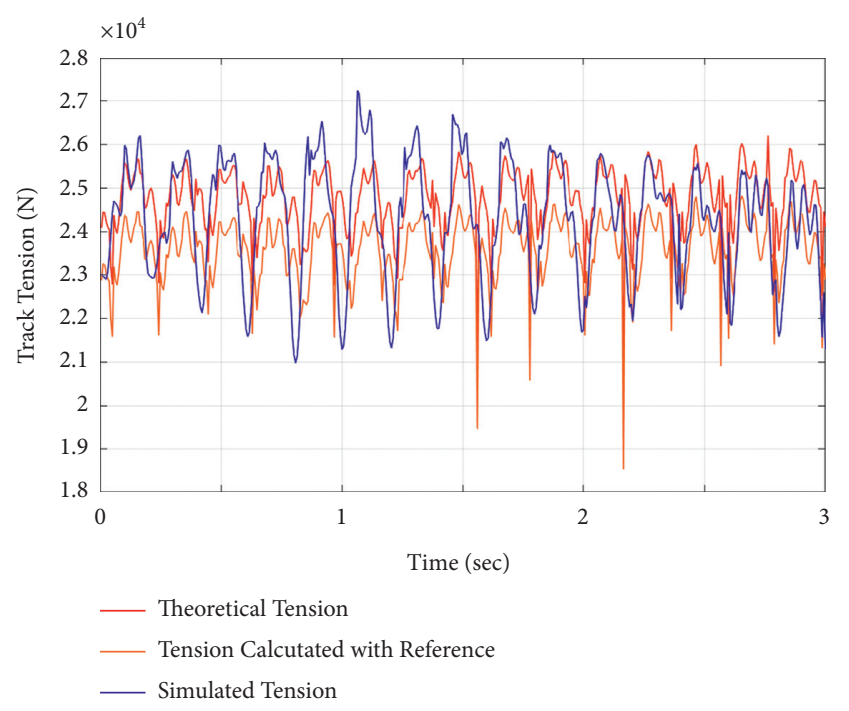

Figure 7: Track tension $\left(F_{4}\right)$ estimation during slow speed.

previous academic research, and the applicability of the formula is verified by setting the soil related mechanical parameters during the simulation via RecurDyn system.

\section{Analysis of Influencing Factors of Track Tension}

5.1. Significance Analysis of Three Factors on Track Tension. In order to analyze the significance of the influence of many factors on the track tension, this paper takes the pretension, the rotation velocity of the sprocket, and vehicle driving road as the orthogonal experimental factors; each factor selects four levels and generates the orthogonal experimental table by SPSS, as shown in Table 2, where $50 \%, 60 \%, 70 \%$, and $80 \%$ of the vehicle weight are taken as the pretension, the rotation velocity of the sprocket is selected as $4 \pi / 3 \mathrm{rad} / s, 2 \pi \mathrm{rad} / s$, $8 \pi / 3 \mathrm{rad} / \mathrm{s}$, and $10 \pi / 3 \mathrm{rad} / \mathrm{s}$, and the driving road is composed of solid, dry sandy, clayey soil, and sandy loam.
The change diagram of the average track tension of estimated calculation and simulated experiments is obtained from 16 orthogonal experiments, as shown in Figure 8. It can be seen from Table 1 and Figure 8 that the variation trend of the tension force $F_{D 1}$ calculated by the theoretical formula is consistent with the simulated results and the mean value calculated by the theoretical formula is also close to that of the simulation, so the validity of the theoretical formula can be further verified. In Table $2, K_{i}$ represents the comprehensive average of data at each level of each factor. It can be seen that the maximum average track tension is $26353.21 \mathrm{~N}$ when the pretension is $80 \%$ of the vehicle weight and the lowest is $17881.52 \mathrm{~N}$, and the range $R$ between them is $8471.69 \mathrm{~N}$. The maximum and minimum corresponding to the rotation velocity of the sprocket and driving road are $21900.64 N, 22080.54 N$ and $21651.17 N, 22363.77 N$, and the range is $179.90 \mathrm{~N}$ and $712.60 \mathrm{~N}$, respectively.

The results of the 3-factor ANOVA obtained according to the data in Table 2 are shown in Table 3. According to the range obtained from Table 2 and the analysis of variance in Table 3, it can be seen that the pretension has an obvious influence on the experimental results and the change of its value will cause a significant change in the tension value.

\subsection{Analysis of Influencing Factors of Track Tension}

5.2.1. Vehicle Dynamics Simulation under Different Pretensions. Pretension is the force received between adjacent track segments when the track link can still maintain uniform tensioning when the vehicle is not driving. Pretension is one of the crucial factors affecting the running vibration of the tracked vehicle and the dynamic track tension. At present, the research on pretension only relies on the experience and experimentation. In order to analyze the effect of pretension on the dynamic tension, $50 \%, 60 \%, 70 \%$, and $80 \%$ of the vehicle weight are taken as the pretension successively. Assuming that the rotation velocity of the sprocket and driving road of the tracked vehicle remain unchanged and the relevant parameters of the tracked vehicle are set according to the dynamic model, the change curve of the track tension under different pretensions can be obtained, as shown in Figure 9.

Simulation data of dynamic tensions with different pretensions are statistically analyzed, the average values are 17541.01 N, 20887.36N, 24239.26N, and 27640.12 N respectively. It can be seen from Figure 9 that the track tension increases due to the increasing pretension and the track tension fluctuates around the average value during the vehicle driving under uniform speed.

5.2.2. Vehicle Dynamics Simulation under Different Driving Roads. The track is in direct contact with the road surface, so the driving road has a great influence on the driving performance of tracked vehicle, especially on soft ground. The vehicle will sink when driving on the soft ground, and the soil enters between the track and the wheel, which has a great impact on the track system. In order to study the influence of different driving road on the track tension, assuming that the 
TABLE 2: Orthogonal test design.

\begin{tabular}{|c|c|c|c|c|c|}
\hline No. & Pretension (\%) & Rotation velocity $(\mathrm{rad} / \mathrm{s})$ & Driving road & Estimated tension $(N)$ & Simulated tension $(N)$ \\
\hline 1 & $1(50)$ & $4(10 \pi / 3)$ & 3 (clayey soil) & 16815.48 & 18265.31 \\
\hline 2 & $2(60)$ & 4 & 1 (solid) & 20195.38 & 19198.33 \\
\hline 3 & $3(70)$ & $3(8 \pi / 3)$ & 3 & 23659.24 & 23321.42 \\
\hline 4 & 1 & $2(2 \pi)$ & 4 (sandy loam) & 16843.31 & 18461.14 \\
\hline 5 & $4(80)$ & 4 & 4 & 27035.85 & 26858.11 \\
\hline 6 & 4 & $1(4 \pi / 3)$ & 2 (dry sand) & 27139.18 & 25196.65 \\
\hline 7 & 3 & 2 & 1 & 23689.51 & 23756.36 \\
\hline 8 & 1 & 3 & 2 & 16848.88 & 18017.66 \\
\hline 9 & 2 & 3 & 4 & 20338.55 & 19642.11 \\
\hline 10 & 4 & 3 & 1 & 27037.49 & 27340.97 \\
\hline 11 & 3 & 1 & 4 & 23626.50 & 24493.73 \\
\hline 12 & 3 & 4 & 2 & 23642.30 & 23363.00 \\
\hline 13 & 1 & 1 & 1 & 16917.07 & 16781.98 \\
\hline 14 & 2 & 2 & 2 & 20304.66 & 20027.39 \\
\hline 15 & 2 & 1 & 3 & 20245.06 & 21130.20 \\
\hline 16 & 4 & 2 & 3 & 27105.34 & 26017.09 \\
\hline K1 & 17881.52 & 21900.64 & 21769.41 & & \\
\hline $\mathrm{K} 2$ & 19999.50 & 22065.49 & 21651.17 & & \\
\hline $\mathrm{K} 3$ & 23733.63 & 22080.54 & 22183.50 & & \\
\hline $\mathrm{K} 4$ & 26353.21 & 21921.19 & 22363.77 & & \\
\hline$R$ & 8471.69 & 179.90 & 712.60 & & \\
\hline
\end{tabular}

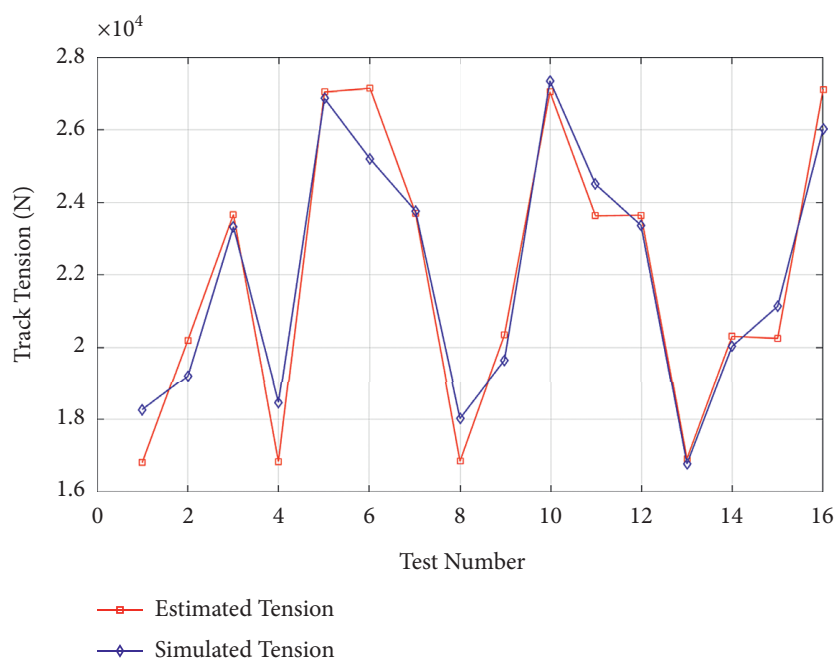

Figure 8: The change of tension in orthogonal test.

TABLE 3: Variance analysis of orthogonal test.

\begin{tabular}{lccccc}
\hline Factors & Type SS & Degrees of freedom & Mean square & $F$ & Significance \\
\hline Pretension & $1.72 E+8$ & 3 & $5.72 E+7$ & 58.62 & 0.0001 \\
Rotation velocity & $1.06 E+5$ & 3 & $3.55 E+4$ & 0.036 & 0.990 \\
Driving road & $1.36 E+6$ & 3 & $4.54 E+5$ & 0.465 & 0.717 \\
Errors & $5.86 E+6$ & 6 & $9.76 E+5$ & \\
Total & $7.92 E+9$ & 15 & & \\
\hline
\end{tabular}

pretension and vehicle speed remain unchanged, four typical road conditions are selected: solid, dry sandy, clayey soil, and sandy loam, and the dynamic changes of track tension are compared.
The driving torque of the driving wheel will be different when the tracked vehicle is driving in different platform, as shown in Figure 10. It can be seen that the driving torque of the tracked vehicle driving on the solid road is greater than 


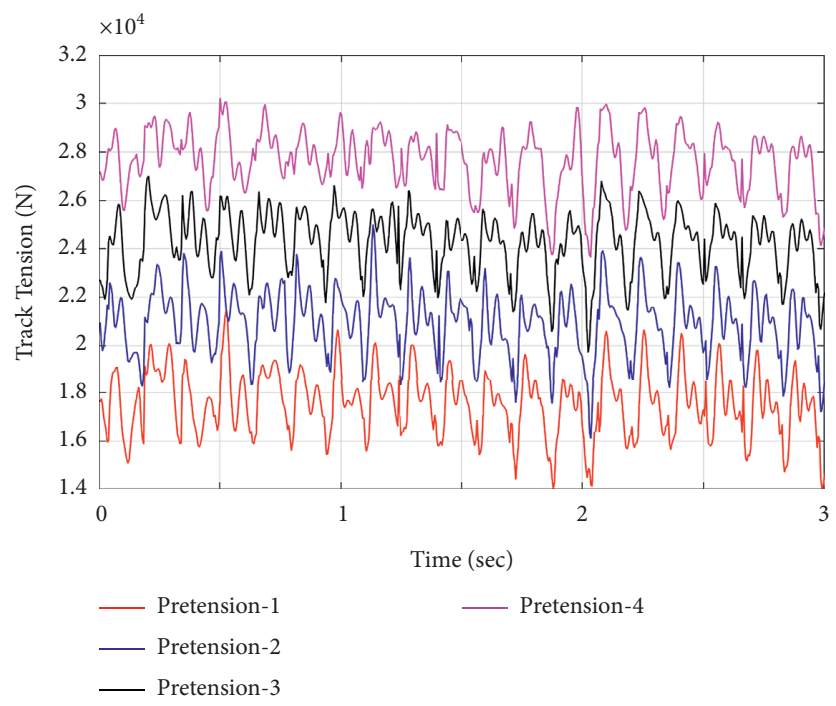

FIgURE 9: Track tension as a function of pretension.

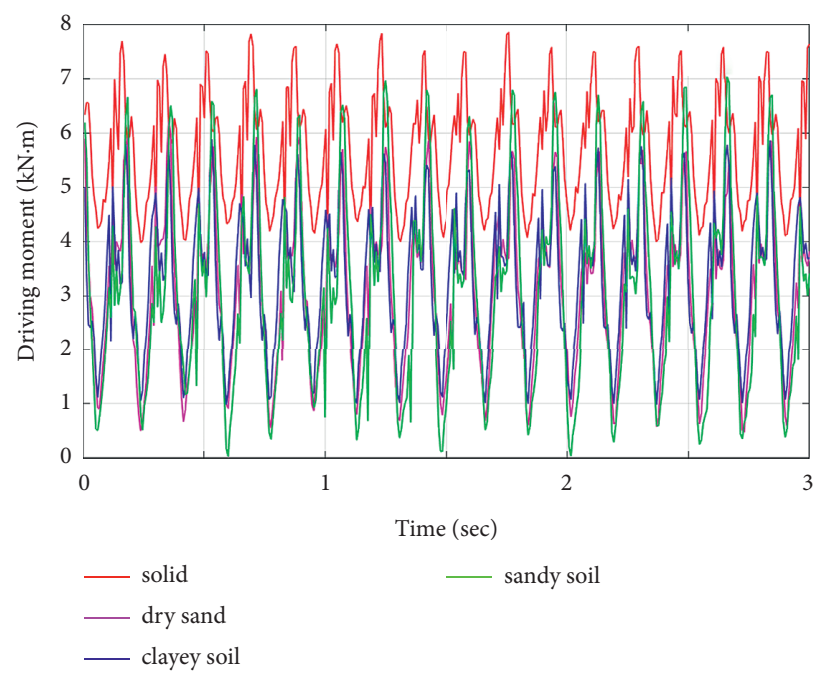

Figure 10: The driving moment of drive sprocket in different landforms.

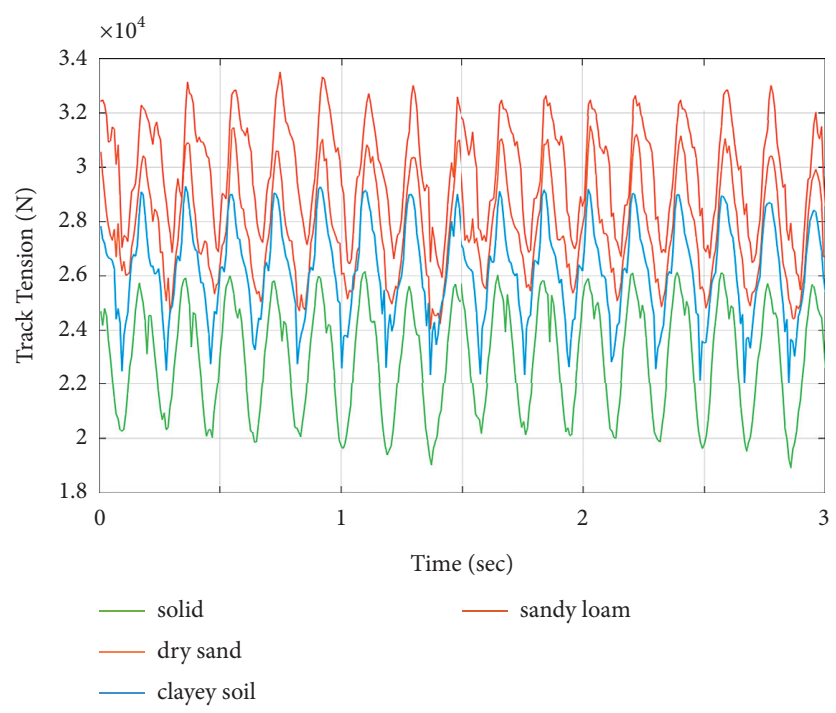

FIgURE 11: The track tensions in different driving road. 
that of the vehicle driving on the soft ground. Figure 11 shows the change curve of track tension in each platform. The green curve represents the change rule of the tension force when the vehicle travels on the solid road, and the other three curves represent the vehicle travelling on the soft ground. It can be seen from Figure 11 that the track tension changes periodically when the vehicle is driving at a constant speed and the track tension when the vehicle travels on the soft ground is significantly higher than the vehicle driving on the solid road. According to the driving moment of drive sprocket in different platform and the simulation results, the track tension decreases with the increase of the driving of moment of sprocket. In addition, the tracked vehicle will have a small range of subsidence when driving on the soft ground, which will hinder the vehicle's progress. And the fine particles of soft soil will also enter the track system. The above factors may result in the greater tension of tracked vehicles on the soft road.

\section{Conclusion}

In this paper, the effect of soft soil on tracked vehicles is discussed based on three-dimensional model; the physical and mechanical properties of the deep-sea sediments are analyzed. In order to estimate the track tension around the sprocket and the road wheels, a theoretical mathematical model is established, and the feasibility is verified with simulated results by using RecurDyn system. And the orthogonal experiment is built to analyze the influence of pretension, the rotation velocity of the sprocket, and driving road on the track tension. The results are as follows:

(1) The three-dimensional model is used to analyze the interaction between track and terrain on soft soil, and the shear resistance of soft soil to the track segment is applied to the mechanical analysis of vehicle track system.

(2) Based on the analysis of the forces on each part of the track system, the theoretical estimation model of the track tension is established.

(3) According to the pressure-sinkage characteristics of soft soil, the relevant soil mechanical parameters of pavement are set in RecurDyn, and the theoretical estimation and dynamic simulation of track tension are carried out under the condition of constant speed. It is concluded that the formula established in this paper can reflect the variation law of track tension, and the error between the theoretical estimation results and the simulation results is within a reasonable range, which verifies the feasibility of the track tension formula derived in this paper.

(4) Through the establishment of orthogonal experiment, the influence of three factors on track tension is studied by combining theoretical estimation and dynamic simulation. The results show that the influence of pretension on the tension of tracked vehicle is the most significant and the track tension increases with the increasing pretension.

The research results of this paper have certain reference significance for the design of deep-sea mining vehicle, but there are still some deficiencies. The vibration and friction energy in the process of vehicle running are not taken into account when the theoretical model of track tension is established, so the next work should be in-depth study of its impact on mining vehicles.

\section{Notations}

$w$ : Width of the blade

$r_{D}$ : Radius of sprocket

$d$ : $\quad$ Operating depth

$F_{i i}: \quad$ Track tension around the idler

$\gamma: \quad$ The effects of density of soil

$F_{t}: \quad$ Pretension

$\psi: \quad$ Soil internal friction angle

$G_{i}: \quad$ Gravity of the idler

$\delta: \quad$ Soil-metal friction angle on the blade surface

$F_{s}$ : Force of soft soil to the track segments

$c$ : Soil cohesion

$F_{f i}:$ Friction between idler and track

$p_{i}$ : $\quad$ Surface force

$F_{c e}$ : Centrifugal force of a track segment wrapping around the idler

$\alpha: \quad$ The rake angle of the blade from the horizontal

$\omega_{i}$ : Rotation velocity of the idler

$\beta$ : $\quad$ Failure angle

$m$ : The mass of the idler

$q$ : $\quad$ Surface surcharge pressure

$I_{i}$ : The mass moment of inertia of the idler

$h$ : Height of the grouser

$B: \quad$ The width of the segment

$\rho$ : $\quad$ Unit mass of track segment

$k_{c}$ : Deformation coefficient of soil cohesion

$F_{j i}$ : The track tensions around the road wheel

$k_{\psi}$ : Coefficient of soil friction deformation

$F_{R x}$ : Longitudinal supporting of the road wheels

$n: \quad$ Soil deformation coefficient

$F_{R y}:$ Lateral supporting of the road wheels

$z_{0}$ : Soil settlement

$G_{j}$ : Gravity of the road wheel

$i$ : Slippage rate

$N_{R j}$ : The normal contact force between the road wheel and track segments

$F_{D i}:$ Track tension around the sprocket

$M_{D}$ : Torque of the sprocket

$m_{j}$ : $\quad$ Mass of the road wheel

$F_{f j}$ : Friction between the road wheel and track

$I_{j}$ : $\quad$ Mass moment of inertia of the road wheels

$\omega_{R j}$ : Rotation velocity of the road wheels. 


\section{Data Availability}

The data used to support the findings of this study are included within the article.

\section{Conflicts of Interest}

The authors declare that they have no conflicts of interest.

\section{Acknowledgments}

This research was financially supported by Shanghai Science and Technology Innovation Action Plan (no. 19DZ1207305) and Shanghai Key Laboratory of Advanced Manufacturing Environment.

\section{References}

[1] Z.-D. Ma and N. C. Perkins, "A track-wheel-terrain interaction model for dynamic simulation of tracked vehicles," Vehicle System Dynamics, vol. 37, pp. 401-421, 2002.

[2] J. Matej, "Terrain-adaptive auxiliary track tensioning system for tracked vehicles," Journal of Computational and Nonlinear Dynamics, vol. 8, Article ID 031013, 2013.

[3] K. Huh, B. H. Cho, and J. H. Choi, "Development of a track tension monitoring system in tracked vehicles on flat ground," Proceedings of the Institution of Mechanical Engineers - Part D: Journal of Automobile Engineering, vol. 215, no. 5, pp. 567578, 2001.

[4] K. Huh, J. Kim, and D. Hong, "Estimation of dynamic track tension utilizing a simplified tracked vehicle model," in Proceedings of the 2001 American Control Conference. (Cat. No.01CH37148), pp. 3335-3340, Arlington, VA, USA, June 2001.

[5] K. Huh and D. Hong, "Track tension estimation in tracked vehicles under various maneuvering tasks," Journal of Dynamic Systems, Measurement, and Control, vol. 123, no. 2, pp. 179-185, 2001.

[6] M. Chalupa, L. Severa, and R. Vlach, "Vehicle track loading simulation," in Proceedings of the 4th International Conference on Machine Vision: Computer Vision and Image Analysis; Pattern Recognition and Basic Technologies, International Association of Computer Science and Information Technology, Singapore, February 2012.

[7] A. M $\square$ żyk, T. Czapla, W. Klein, and G. Mura, "Numerical simulation of active track tensioning system for autonomous hybrid vehicle," Mechanical Systems and Signal Processing, vol. 89, pp. 108-118, 2017.

[8] X.-T. Huang, L. Gu, X.-G. Zhu, and W.-W. Lü, “Track tension and its distribution on track link," Journal of Beijing Institute of Technology (Social Sciences Edition), vol. 36, pp. 226-230, 2016.

[9] X.-T. Huang, L. Gu, X.-G. Zhu, and C.-B. Yang, "Track tension and its influencing factors," Acta Armamentarii, vol. 35, pp. 1110-1118, 2014.

[10] P. Wang, X. Rui, and H. Yu, "Study on dynamic track tension control for high-speed tracked vehicles," Mechanical Systems and Signal Processing, vol. 132, pp. 277-292, 2019.

[11] Z.-F. Wang, B. Liu, and L. Zhai, "Track tension analysis of four-wheel drive tracked vehicles," Journal of Beijing Institute of Technology (Social Sciences Edition), vol. 26, pp. 45-49, 2017.
[12] S.-W. Pan, X.-G. Ma, X.-M. You, M. Ye, and X Gong, "Analysis of tension force in tracked vehicle running system," Journal of Shenyang Ligong University, vol. 32, pp. 57-59, 2013.

[13] E. McKyes and O. S. Ali, "The cutting of soil by narrow blades," Journal of Terramechanics, vol. 14, no. 2, pp. 43-58, 1977.

[14] J. Li, Q. Li, J.-K. Zhou, and Y. Zhang, "Analysis of trackterrain interaction on soft soil," Acta Armamentarii, vol. 33, pp. 1423-1429, 2012.

[15] L. Li and S.-L. Li, "Simulation and mechanical characteristics of terramechanics of the surface soil on deep-sea bed," Engineering Mechanics, vol. 27, pp. 213-220, 2010.

[16] J.-Y. Wang, W.-G. Cao, and Y.-C. Zhai, "Experimental study of interaction between deep-sea sediments and tracks," Rock and Soil Mechanics, vol. 32, pp. 274-278, 2011.

[17] X.-L. Chen, "The physical properties of surface sediments in oceanic polymetallic nodule," Donghai Marine Science, vol. 22, pp. 28-33, 2004. 